\title{
Towards A Regional Science Academy: A Manifesto
}

\author{
Peter Nijkamp ${ }^{1}$ and Karima Kourtit ${ }^{23}$ \\ ${ }^{1}$ Free University of Amsterdam, Amsterdam, The Netherlands (email: p.nijkamp@vu.nl) \\ ${ }^{2}$ KTH Royal Institute of Technology, Stockholm, Sweden (email: karima.kourtit@abe.kth.se)
}

3 in collaboration with the founding members:

Abdellatif Khattabi, Adam Rose, Adriana Kocornik-Mina, Alessandra Faggian, Allen Scott, Amit Batabyal, Ana Maria Bonomi Barufi, André Torre, Andrea Caragliu, Anna Lundgren, Antoine Bailly, Arthur Getis, Aura Reggiani, Bob Stimson, Cathy Macharis, Charlie Karlsson, Euijune Kim, Dani Shefer, Daniela Constantin, Daniel Griffith, Daisuke Nakamura, Daniel Czamanski, David Plane, Edward Glaeser, Elizabeth Mack, Eduardo Haddad, Fabio Mazzola, Folke Snickars, Genevieve Giuliano, Geoffrey Hewings, Gordon Mulligan, Gunther Maier, Haifeng Qian, Hans Westlund, Harry Richardson, Henk Folmer, Henk Scholten, Jacques Poot, Jean-Claude Thill, James LeSage, Janet Kohlhase, Joao Romao, Johannes Broecker, John Östh, Juan Carlos Martin, Juan Cuadrado-Roura, Karst Geurs, Kieran Donaghy, Kingsley Haynes, Klaus Zimmermann, Laurie Schintler, Lay Gibson, Luc Anselin, Luigi Fusco Girard, Manfred Fischer, Mark Partridge, Marlon Boarnet, Martin Andersson, Masahisa Fujita, Michael Batty, Michael Carroll, Miruna Mazurencu Marinescu, Milan Bucek, Neil Reid, Oto Hudec, Patricio Aroca, Peter Batey, Peter Taylor, Philip Cooke, Rachel Franklin, Randall Jackson, Richard Florida, Roberta Capello, Roberto Camagni, Roger Stough, Ron Boschma, Sandy Dall'Erba, Saskia Sassen, Serge Rey, Soushi Suzuki, Tigran Haas, Tomaz Dentinho, Tschangho John Kim, Uwe Blien, Vicente Royuela Mora, Waldemar Ratajczak, Waldo Tobler, Wolfgang Lutz, Yoram Shiftan, Yoshiro Higano, Yuyuan Wen.

Received: 22 January 2016/Accepted: 22 January 2016

\begin{abstract}
This Manifesto provides a joint proposal to create a Regional Science Academy as a think-tank support platform for a strategic development of the spatial sciences. The Regional Science Academy is a strategic spatial knowledge catalyst: it acts as a global intellectual powerhouse for new knowledge network initiatives and scholarly views on regions and cities as vital centrepieces of interconnected spatial systems. This contribution highlights its role and presents various activity plans.
\end{abstract}

'All the forces in the world are not so powerful as an idea whose time has come' Victor Hugo

\section{Prologue}

'The most dangerous worldview is the worldview of those who have not viewed the world'

Alexander von Humboldt

Over the past months, various scholars with a deep professional interest in the spatial sciences have met in varying compositions and on different occasions to discuss the strong and weak points in the spatial sciences, in particular from the perspective of their future vitality, with a view to identifying promising opportunities that would make a difference. Their intensive discussions were prompted by a widely shared concern on the lack of innovativeness, vibrancy, and external recognition of the spatial sciences. 
There was a general consensus that some sort of academic 'think tank', driven by original brainstorming activities, is a critically needed vehicle to ensure the necessary innovation and dynamics in this important field of research and policy.

Such a novel initiative should be organised from the bottom up, on the basis of voluntary efforts, and produce seminal contributions of dedicated scholars and experts for the whole world of the regional sciences. It would act as a catalyst for innovative and free academic thinking, and in the execution of its tasks be relatively independent from existing scientific organisations in the domain of the spatial sciences. The operation of such a 'think tank' initiative should not be directly controlled by the vested - though useful - interests of existing organisations and agents, but should operate at arms' length of existing bodies as a decentralised service network of scholars. It should be conceived of as a voluntary, bottom-up driven platform for the generation, identification, promotion and diffusion of new ideas in the spatial sciences, with a view to their future dynamism. The institutional organisation of this scholarly initiative should be light and flexible, and would operate most fruitfully under the wings of the Regional Science Association International.

\title{
'The doors of wisdom are never shut' Benjamin Franklin
}

It would be called the Regional Science Academy; it would clearly have a much broader constituency and membership than the Regional Science Association International in a strict sense. It would act as a voluntary intellectual service team ('a supporters club') with the aim to strengthen the long-term perspectives and strategies of existing organisations by offering original and scholarly insights. It would share new insights from the perspective of forward-looking intellectual contributions with the worldwide regional science community in its broadest sense.

\section{'If we wait until we're ready, we'll be waiting for the rest of our lives' Lemony Snicket}

The present strategy document 'Towards a Regional Science Academy' outlines the various ambitions and plans that have been formulated in cooperation with a large and varied group of founding fathers/mothers from all over the world. The focus of the planned activities will, in particular be on:

- Ideas: exploration of forward-looking and innovative regional science concepts, new spatial theory and methodology, new perspectives on policy, etc.

- People: integration of young scholars and broadening of geographical scope, so as to create new seedbed conditions for original thinking worldwide.

- Data: sharing of information in a 'big data' world (e.g. data warehousing), so as to foster worldwide cooperation among spatial scientists.

\section{Regional Science in Perspective}

\author{
'It's not enough what I did in the past - there is also the future' \\ Rita Levi-Montalcini
}

The broad field of the spatial sciences comprises a wide variety of (multi)disciplinary orientations and domains, such as regional economics, urban economics, geography, regional science, political science, demography, business management, transportation science, land-use planning, urban architecture, heritage management, environmental science, and so forth. This amalgam is also reflected in a great diversity of distinct and unconnected scientific and professional organisations, which are often operating in infertile isolation from each other. There is no systematic and translational synergy and coherence in planning and programming new scientific endeavours that are strategic and 
long-term-oriented. This is a regrettable situation which forms a sharp contrast with many other disciplines and science domains, where 'think-tank' strategies and operations at an international level have become quite common. Lack of forward thinking - with regards to both ideas (cognitive capital) and people (human capital) - is detrimental to a field that is central to the future of our world.

The spatial future of the planet is a source of much uncertainty and deep concern for both scientists and policymakers, as is clearly witnessed in the recent Paris Declaration (2015) on climate change.

'Imagination is more important than knowledge. For knowledge is limited, whereas imagination embraces the entire world, stimulating progress, giving birth to evolution. It is, strictly speaking, a real factor in scientific research'

Albert Einstein

Regional science seeks to enrich the multifaceted social science research domain by coping with - and addressing explicitly - the often prevailing, but clearly restrictive assumption of a 'wonderland of no spatial dimensions' in the traditional social sciences. It started in the 1950s from a dedicated and convincing scientific mission, in which the impact of spatial opportunities on, and obstacles to, regional and urban development and of spatial interactions assumed a central place. The analytical focus through which these phenomena were investigated - usually from a multidisciplinary and evidence-based orientation - formed a distinct, prominent and recognised feature of regional science in comparison to established disciplines, such as geography, political science, urban and regional planning, transportation science, environmental science, etc. For many spatial science researchers, regional science is not their original and only discipline, but it is often complementary to their initial and single 'home discipline'. The degree of 'self-identity' of regional science - or the spatial sciences in general is generally rather low. In essence, regional science is an amalgam of various disciplinary approaches with a core focus on space. This key characteristic has an indigenous strength due to its ability to build bridges between various approaches, but also reflects a weakness, in that a uniform or broadly accepted theoretical and methodological framework is lacking.

\section{'I have never cared for particular disciplines' Carlos Adrian}

It is remarkable that regional science - in a more narrow sense than the spatial sciences has witnessed a surprisingly rapid pace of growth over the past few decades. Conferences of more than 1000 participants are today no exception. So, in a way, regional science is not only alive and well, but even booming. Its favourable development is supported by a well-functioning institutional framework based on a decentralised and bottom-up constellation (RSAI, supraregional bodies, and a large number of national or language sections), all characterised by a great scholarly commitment.

This model has manifested itself as a rather robust and successful organisational structure. It has laid the foundation for a professional organisation of numerous regional science meetings. Of course, at times there may be a need for change or gradual evolution in structures and bodies, depending on new scientific developments or shifts in the geographical presence of national sections. But such emerging issues can effectively be handled within the existing and well-functioning managerial and institutional mechanisms of the RSAI (including various Councils such as ERSAC, NARSC, PRSCO, WRSA, etc., as well as the RSAI Long Range Planning Committee). In conclusion, the future of regional science looks bright and sustainable. However, a sustainable vital science also needs forward-looking views and perspectives beyond the present horizons, satisfactory as they may be for the time being. This is the focus of the present Manifesto. We now first offer a critical reflection on the ineffectual way in which strategic future research in the spatial sciences is programmed at present. 


\section{Change is Pertinent!}

'Never leave that till tomorrow which you can do today'

Benjamin Franklin

Our planet is currently facing a wide variety of challenges - both local and global which - if not effectively addressed - will have far-reaching impacts on human well-being and quality of life in the future. Examples of such megatrends are: rapid population growth in developing countries; ageing in the OECD-part of the world; a worldwide rise in migration flows (voluntary and forced); threatening climate change effects (such as sea-level rise and extreme weather conditions); food and water shortage; increasing spatial disparities; emergence of radical and extremist ideological movements; fears for a loss of security; and so forth.

The spatial projections of such worldwide trends are increasingly visible on our planet. Examples are: the rapid rise of urbanisation; the unprecedented explosion of mobility in many countries; alarming environmental conditions; paralysis in spatial (urban, regional, transportation and environmental) planning, etc. The various threats to - and opportunities for - the spatial quality conditions on our earth are often mentioned, but insufficiently addressed and thought through from a scientific perspective. This is clearly witnessed in the lack of a solid and broadly shared strategic research agenda and related actions taken on the spatial future of our world. The reasons for this regrettable situation are manifold, but are certainly related to weak programming mechanisms on future strategic research in the spatial sciences; which can be summarized as follows:

- The development of the spatial sciences is mainly based on incremental amendment to existing paradigms;

- A major part of research in the spatial sciences follows standard recipes, and is hampered by methodological path dependence, rather than being encouraged to be innovative;

- There is a lack of systematically organised science-dynamics systems which aim to develop forward-looking research strategies based on outside - rather than inside science perspectives from other disciplines;

- Insufficient innovation in the spatial sciences is also caused by the lack of broadly shared mechanisms for societal demand articulation;

- Unsatisfactory linkage systems prevail in regard to promising developments in other disciplines such as the trend towards data-driven research or data-driven theory development;

- Lack of sufficient integration of different, but complementary disciplinary perspectives (e.g. geography, regional economics, urban economics, political science, urban planning and architecture, transportation science, urban and rural sociology, environmental science, social health science, real estate and cultural heritage management, demography, geo-science, et.) leads to weak policy impacts.

\section{'Above all, don't fear difficult moments. The best comes from them'}

Rita Levi-Montalcini

All these inadequate elements have been detrimental to a sound and sustainable development of the spatial sciences, including regional science. There is an urgent need for a drastic change in the management of the design process of innovative science dynamics in the spatial sciences, including regional science. Regional scientists may be expected to take the lead in addressing the major future challenges that have far-reaching implications for the spatial future of our earth. 
4 Challenges Galore

'Don't limit your challenges; challenge your limits'

Jerry Dunn

Regional science is characterised by a multidisciplinary orientation. At the same time, there are other related multidisciplinary domains, such as environmental science, transportation science or urban architecture, all dealing with space, and all have their own, professional - often international - organisations. Hence, synergy and symbiosis driven by a jointly shared vision or paradigm is largely lacking. Well thought-out strategies oriented towards 'bonding and bridging', in and between these domains, might create unforeseen opportunities for the spatial sciences. There could be a great potential for regional science to foster in a convincing way intellectual leadership in the broad domain of spatial sciences. Arbitrary examples of challenging issues to be addressed might be: city growth with increasing sustainability; sea-level rise with increasing safety; ageing societies with increasing dynamism; mass migration with increasing societal cohesion; new technologies with increasing human scale, etc.

A vibrant regional science needs to be responsive and creative. However, remaining bright and robust as a scholarly challenge also requires a new scientific spirit that will prompt innovative thinking, now and in the future. Even though national and international regional science conferences and workshops are splendid and necessary vehicles to present and disseminate new knowledge, they are not the proper or exclusive tools for generating attractive seedbed conditions for creative and original ideas which can evolve into new paradigms or radically new ideas for regional science. Our world is full of unprecedented and other unknown - challenges, which call for an open habitus that is not characterised by 'more of the same'. Such challenges are abundantly present, e.g. climate change, mass migration, ageing, demographic change, new technologies, territorial conflicts, ethnic tensions, mega-city development, etc. All such emerging phenomena call for 'fresh' thinking. The achievement of this unconventional goal would require, as in many other disciplines, a different academic and organisational mode of research in the form of a forward-looking academic 'think tank' of dedicated scientific experts and 'great minds'. In addition, a vital regional science is not only about conducting research, but also about preparing for the next generation of scientists, e.g. through education and training. Since regional science is often a complementary scholarly activity - including regional economics, geography, urban planning, political science, transportation science, land use planning, architecture, environmental science, etc. - it seems pertinent to have - or to build - also strong liaisons with the manifold disciplinary constituencies, not only on the practical side but also on the academic side. And finally, the innovative capacities of the young generation also need to be exploited, as many new ideas do not originate from the learned minds of 'grey-haired' scholars, but from more imaginative and less restricted brains of young scientists.

\section{'We choose to go to the moon in this decade and do the other things. Not because they are easy, but because they are hard' John F. Kennedy}

Consequently, there is a need for a new type of learning mode in the spatial sciences, in which a cross-section of older and younger regional scientists takes - and shares responsibility for the intellectual evolution - or perhaps a radical transformation - of regional science, with a strong emphasis on new theory and concepts, as well as on novel modes of research. Such a smart organisation of 'great minds' by regional scientists cannot be organised in a top-down, hierarchical fashion. It is the free mind that is decisive for the intellectual future of any science, including regional science. What is needed in a complex regional science organisation and constellation is a group of dedicated and committed scholars - preferably with a balanced age, gender, geographical and disciplinary composition - that is able and willing to provide intellectual services with a view to a sound and dynamic future for regional science. This brings us to the idea of a Regional 
Science Academy, as a voluntary, decentralised, and scholarly network centre for spatial scientists worldwide. Its objective would be to help contribute to the future vitality of regional science and related disciplines, by offering daring and forward-looking ideas, new forms of cooperation, and new research initiatives.

Thus, the Regional Science Academy is to be a voluntary, bottom-up-driven platform for the generation, identification, promotion and diffusion of new ideas in the spatial sciences. The need for an active and proactive think tank in regional science is even more urgent in the current times, as regional science is more or less reaching a stage of maturity. Maturity - as growth cycle theory purports - calls for innovative actions, especially when there are many policy and research challenges ahead.

In this context, it is noteworthy, that the RSAI has about 4,500 members around the world, organised in 32 sections and 4 supranational associations. This broad field involves more than 30 scientific journals and book series, thus creating and promoting a resilient science through the organisation of many regional science conferences, workshops and congresses, and interconnecting academics, students and experts from many universities and research institutions. The potential to grow is great: if we take into account that the more active RSAI sections in our world have approximately 10 members per 1 million inhabitants, it is plausible to foresee that in the course of time the RSAI may be able to reach about 50,000 members around the world and that through good science and education initiatives it is able to promote sustainable regional development globally. Regional science has the potential to make a difference!

The dynamism of the spatial sciences all over the world has also produced remarkable achievements: Nobel Prizes, NECTAR meetings, ICOMOS workshops, REAL sandwich PhDs and visiting exchanges, ERSA and RSAI summer courses, NARSC workshops, Tinbergen Institute workshops, the diffusion of main Regional Science Schools, and many other initiatives that resulted from the embedded activism of members, sections and supranational bodies. Yet, and at the same time, there is a disturbing and uneasy gap between the theoretical framing of regional science and the practice of regional economic development, as well as between regional science research and regional science education. For example, we have witnessed recent developments towards a 'New Economic Geography' or a 'New Spatial Economics', which address issues related to spatial imbalances in a more emphatic way, from the perspective of the rising importance of 'city-regions' (with many positive and negative externalities) in a dynamic space-economy. Such developments raise intriguing questions on whether the traditional foci of regional science research and education are still relevant.

\section{'Discovery consists of looking at the same thing as everyone else and thinking something different' \\ Albert Szent-Györgyi}

An operational idea may be to identify a set of critical issues that fall within the ambit of regional science, and to organise small teams of scholars to develop appropriate multitask research agendas that, if pursued, might lead to viable solutions. Such experiments might also enhance the credibility of solid regional science research, and lead to its broader acceptance in regional development policy and practice.

It is clear that the future of regional science cannot be left to blind and coincidental forces, but calls for careful thinking. Clearly, a central research coordination (e.g. in the vein of EU FP7 programmes) will be detrimental to creativity and resilience in regional science. This concern ties in with the need for new and future-oriented thinking. An intermediate, flexible and open way of ensuring a vitality and adaptation in regional science research and education is likely the best option, with great promise for a vital future. It would serve the broad field of all spatial sciences, without being subordinate to one of the existing organisational bodies in this field. And, therefore, the idea of a Regional Science Academy may be viewed as a valuable and realistic opportunity and even as an urgent necessity for a vibrant research domain in the spatial sciences. This task will be further outlined in the next section, where some principles of this new organisation will be highlighted. 


\title{
5 The Regional Science Academy: Vision and Mission
}

\author{
'Vision is the art of seeing the invisible'
}

Jonathan Swift

The Regional Science Academy is to be an independent and balanced 'flat' network of recognised, dedicated and active scholars in the spatial sciences, who seek to promote a sustainable future for regional and urban development around the world through scholarly contributions to regional science. This vision is based on advanced regional science theory, research and education, and is envisioned to be achieved through innovative and forward-looking intellectual contributions and initiatives. Its members are committed to share their scientific talents with, and to provide scholarly services to, the regional science community at large on a voluntary basis. This initiative is not born out of criticism of the functioning of existing bodies, but out of the need to support and reinforce the research community in the domain of the spatial sciences. In summary, this ambition can be formulated in the following corporate vision:

\section{Corporate vision}

The Regional Science Academy is a strategic spatial knowledge catalyst: it acts as a global intellectual powerhouse for new knowledge network initiatives and scholarly views on regions and cities as vital centrepieces of interconnected spatial systems.

The added value of the Regional Science Academy can be highlighted by focusing on the realisation of the following overarching aims related to its long-term corporate vision, which is to:

- Enhance the critical role of regions and cities worldwide as vital, livable and sustainable places with a high quality environment for living and working;

- Develop the foundations for an integrated regional theory and methodology, perhaps by starting to reflect on the background and foundations of regional science;

- Design socio-economic, ecological and planning ground-level research that is policyoriented and innovation-driven;

- Provide the scholarly and policy tools for developing, assessing, and aiding the effective implementation of research, with a view to tackling future challenges for regions and cities all over the world, based on a merger of serendipity-driven and client-oriented research.

- Develop communication mechanisms for sharing the knowledge base in the regional science field, in particular by addressing novel and path-breaking perspectives on regional science research.

- Nurture the future of spatial analysis by addressing forward-looking models (e.g. models of change and shocks) and plans ('Burnham-style operations').

- Act as an intellectual platform for exchanging creative knowledge on spatial (regional, urban, geographical or transportation) development, in cooperation with a younger generation and with scholars from emerging and developing countries.

- Design original and practical regional science curricula descriptions that ensure a high quality, form the basis for accreditation, and shape a new generation of young regional scientists. 


\section{'We need to understand what we can do and how. Otherwise we will never do it' Constantinos Apostolou Doxiadis}

Clearly, some realism is needed as well. All such high ambitions cannot be realised at the same time. A step-by-step and balanced priority strategy will be needed to ensure steady progress and to avoid disappointment. Dedicated individual efforts - organised at a collective level - will be needed to implement priorities and to support the unfettered rise of new ideas, concepts and methods. Consequently, a careful programming - including prioritisation - of voluntary activities in the spatial sciences would need to be based on a commonly shared, professional business plan, driven by a mission statement. What is then the mission of a Regional Science Academy?

\section{Mission statement}

The Regional Science Academy is a service-oriented scholarly network for rethinking and managing the spatial dynamics of people and socio-economic activities in connected and complex spatial systems of our earth by:

- developing new interdisciplinary knowledge and knowledge initiatives for strengthening regions and cities as liveable, vital and resilient places;

- creating and exploiting scientific synergy - and related smart governance action - on regional and urban development, from an economic, social, demographic, policy, cultural, logistic, mobility and innovation perspective, at different spatial scale levels.

The Regional Science Academy aims, therefore, to generate original (sometimes radical) and creative ideas, concepts and initiatives that benefit regional scientists and society all over the world, in particular, through the execution of the following action plans:

- To act as a catalyst for the genesis of novel and original future-oriented cornerstones for a vital regional science including, in particular, novel conceptualisations, new theoretical paradigms, innovative methodologies, unconventional application fields, or proactive and smart governance mechanisms;

- To favour the dissemination of the body of regional science knowledge towards various interest groups, such as scholars from related and sometimes distant disciplines, policymakers and planners, or the business community, so as to provide novel liaison services for effective solution-oriented contributions to sustainable regional and urban development; the regional science community should be able to develop a new habitus or collective ethos, where 'solutions on demand' might be created;

- To map out, synthesise and monitor a wide array of educational, teaching and training programmes in regional science in different educational institutions or places worldwide, at the Bachelor, graduate/postgraduate/research Master level, with the aim to form a clearing house for advanced regional science education, which may provide guidelines for the development of curricula in regional science and related disciplines (e.g. textbooks used, recognition and certification of programmes, sandwich PhDs, twinning programmes, summer courses, etc.);

- To ensure a permanently vital development of regional science through the active involvement of young promising regional science scholars - for instance, through a Young Chamber of the Regional Science Academy (with a relatively independent constituency) - so that the 'next gen' can act as a source of new research ideas, or for shifting boundaries (e.g. happiness research, social justice, ageing, sustainable spatial development, e-research, human health, global logistics, global urbanisation, resource ownership, safety research, forced migration, etc.). 
The Regional Science Academy will have, by its very nature, an inclusive stature that is different from the RSAI Fellows system. The latter class is an exclusive and respected group of talented and recognised scholars in regional science who received their honorary position on the basis of their past performance (i.e. high-quality contributions to regional science research); it is a honorary position without any further direct commitment. The Regional Science Academy is much more a voluntary intellectual workhorse with the dedicated aim to provide to the worldwide community of regional scientists a wealth of academic services that are forward-looking and strategic in nature, so as to ensure a sustainable vitality of regional science research in a broad and advanced global research and knowledge arena. Its role is purely supportive and complementary to the existing activities of the RSAI and its related bodies; by no means should it be competitive with existing initiatives. It is inclusive, with the aim to connect the multifaceted world of the spatial sciences through scholarly network initiatives, originating from the 'free mind' of spatial scientists all over the world.

\section{'If I have seen further than others, it is by standing upon the shoulders of giants'} Isaac Newton

It is thus foreseeable and realistic that the Regional Science Academy will be an independent institution for complementary strategic and intellectual service provision for the spatial sciences, with close links to the regional science community. At its meeting on 27 Augustus 2015 (Lisbon), the RSAI Council generously offered to support the Regional Science Academy, under the aegis of the RSAI. Clearly, it will function as a broad umbrella institution for all fields in the spatial sciences.

\section{Organisation}

'Make men work together; show them that beyond their differences and geographical boundaries there lies a common interest' Jean Monnet

The formal roles and tasks of the Regional Science Academy and its members, as well as its institutional structure, are to be described in its Constitution and its By-laws, which will have to be the first priority in the Academy's work plan. This section only offers some first consensual ideas on the ways to proceed.

\subsection{Membership}

The Regional Science Academy is not institutionally oriented, but based on the renowned expertise of dedicated individuals with expertise in the spatial sciences. The founding members of the Regional Science Academy should agree on the rules and guidelines of membership, and should feel committed to it. Membership should be based on commitment to the goals of the Academy and to its ambitious scientific contributions and qualifications. Consequently, the Regional Science Academy comprises spatial scientists who:

- Have a proven record as a dedicated and recognised leading scholars in regional science;

- Are explicitly committed to help implement the basic goals of the Academy;

- Are expected to play an active role in the pursuit of regional science initiatives, in particular:

- through participation in forward-looking 'think tank' and 'great mind' activities;

- through the organisation (including sponsorship) of road map workshops or advanced brainstorm carrefours (ABCs) for encouraging innovative regional science research perspectives; 
- to assist in teaching and supporting 'out-reach' activities in regional science curricula worldwide;

- to offer stimuli to young regional science researchers by inviting them for a 'refreshment stay' or to participate in collaborative work (e.g. through a pairing system).

It seems plausible that the total membership in number may range from 70 to 150 in a fully mature stage. After the founding stage, a system of application, admission, and selection needs to be developed and put in clear terms in the Statutes (see later). It seems plausible to assume that any recognised regional scientist who offers a concrete promising activity in accordance with the goals of the Regional Science Academy qualifies, in principle, to be a member. It may also be wise and useful to think of a rotational system where membership of the Regional Science Academy might be restricted to a term of 5 years (perhaps, with a prolongation of one more term). Such membership issues have to be further formulated in the Constitution and its By-laws.

'There is no more powerful engine driving an organization toward excellence and long-range success than an attractive, worthwhile, achievable vision for the future, widely shared'

Burt Nanus

\subsection{Activities agenda}

The Regional Science Academy would have to avoid overlapping activities with other RSAI activities or activities from related institutional bodies (e.g. NECTAR). It ought to provide complementary services to existing RSAI members and members of other bodies in the spatial sciences. Examples of such an operational and executive agenda could be:

- Programmes to create new innovative ideas or concepts in the spatial sciences; the need for a solid theoretical foundation of regional science ('regional theory') is pertinent;

- Programmes to raise regional science questions of an intellectual nature that are as yet not being addressed and to present these to international fora;

- Programmes that are motivational for young and promising scholars in the field (e.g. those belonging to a Young Chamber of the Academy - see the next point);

- 'Next gen' initiatives for students: they will not only be targets of training/education, but the Academy will also create agendas for and with them, e.g. through the vehicle of a Young Chamber of the Academy (to be decided at a later stage);

- Encouragement for new forms and/or types of intellectual leadership in regional science (with a particular view to non-conventional thinking);

- Involvement of leading scholars from fields other than regional science (given that it is interdisciplinary and not a single discipline), including - but not limited to traditional affiliated fields such as geography, transportation, logistics, planning, administrative science, economics, visual and performing arts, business, law and the environmental sciences. Other fields that are likely to offer new concepts and theories that could be adapted to investigate and model regional science issues and problems of a spatial nature may include archaeology, history, physics, chemistry, biology, bio- and medical science, sociology, psychology, architecture, engineering;

- Development of web-based open platforms to share new research, teaching resources or curricula, which can be replenished on a voluntary basis and freely accessed by all ('open regional science'). 


\title{
6.3 Administrative aspects
}

- The Regional Science Academy is an interactive social network of scholars that should have the lightest network structure possible. It may be administratively managed by a recognised and experienced regional science scholar with a sufficient institutional backing. Of course, there should be a Board (chaired by a President, and perhaps supported by two Vice-Presidents, and perhaps some additional five to eight more members overseeing and coordinating all operations). Other aspects to be considered in the Statutes are, inter alia: a kind of efficient administrative infrastructure to provide planning, project support and sustained effort;

- A funding mechanism for start-up activities, as well as for sustained efforts. A focus on innovation processes and outcomes might be a way to create a funding mechanism, e.g. on the basis of a working group whose members have entrepreneurial experience;

- Marketing/public relations as a dissemination tool, for both the scientific community and the users at large;

- A communication infrastructure - newsletters, periodic news releases, white papers (perhaps with stamps of approval), etc.

\author{
'If you can dream it, you can do it' \\ Walt Disney
}

Clearly, the Statutes and the working rules will be instrumental in implementing the action strategy sketched above. We will now address some first initial actions.

\section{Modus Operandi}

\author{
'Regions of the world, unite! You have nothing to lose but your borders' \\ Güney Celbiş
}

The various preparatory brainstorming sessions held in various places - Rabat, Amsterdam, Poznan, Lisbon, Portland - offered ample time and opportunity to discuss in greater detail the operational steps originating from the corporate vision and mission statement of the Regional Science Academy. Using the path-breaking Doxiadis' cruise experiment (1963) as a role model - which led to the influential and seminal Delos Declaration in 1963 - in the various preparations both strategic headlines and operational tasks and pathways were discussed in a consensual way, taking into consideration the necessity to establish a Regional Science Academy which is both attractive and viable. In this way, the foundation stones for a promising initiative could be laid in the interests of the regional science community at large, so that the Regional Science Academy can serve as a signpost for future regional science activities which really matter and make a difference.

\section{'The empires of the future are empires of the mind' Winston Churchill}

Both strategic and operational tasks and issues have been addressed in the preparatory meetings, but they need of course more elaboration and focus. From a practical perspective on the identification of concrete action plans described in the next section, a systematic scanning and scoping approach turned out to be helpful. The following schema (Figure 1) was, and may be, instrumental in structuring the emerging ideas on the viability and future orientation of a Regional Science Academy. It aims to offer a coherent design map for future activities. It is clear that the formulation of a road map for the Regional Science Academy is a matter of joint interaction among its members and its clients, and needs to be reiterated at regular time intervals. 


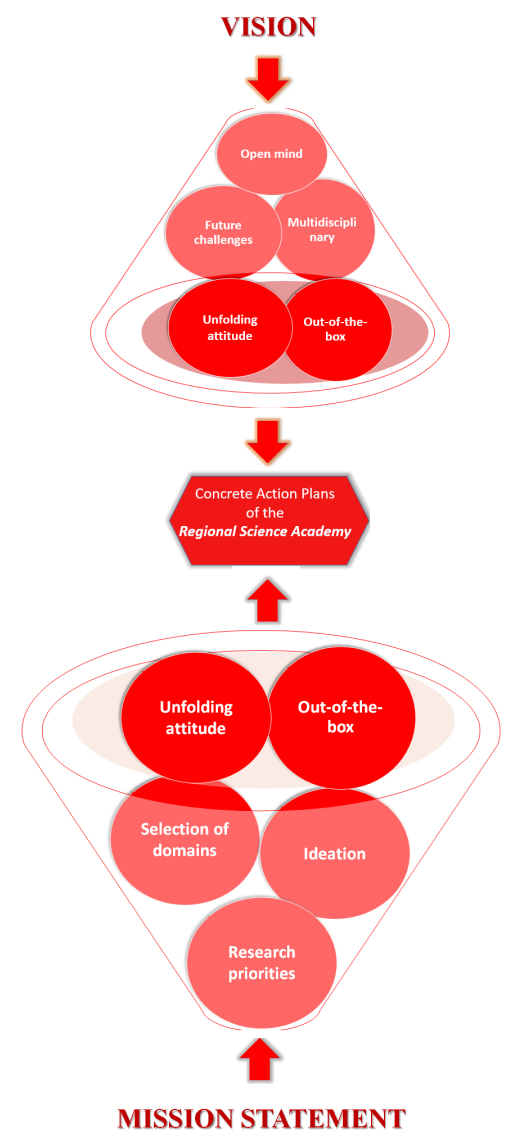

Figure 1: Regional Science Academy Action plans

\section{Concrete Action Plans}

'Vision without action is a daydream. Action with without vision is a nightmare' Japanese Proverb

The idea of a Regional Science Academy has spurred a wealth of new plans and actions by various enthusiastic participants that can meaningfully be taken on board and put in operation by motivated members. From the great variety of proposals and enthusiastic ideas, we have composed four long-term activity fields, from which a diversity of concrete actions plans can be derived in the form of four work packages for these key actions ${ }^{1}$. These activity fields are shown in Figure 2.

It goes without saying that these four activity fields represent four interconnected perspectives of the Regional Science Academy. These four activity fields will be described in slightly greater detail in the remaining part of this section. Next, we make a number of suggestions on how to put these concrete tasks in action.

'You've got to think about big things while you're doing small things, so that all the small things go in the right' direction'

Alvin Toffler

\footnotetext{
${ }^{1}$ Part of this workplan was inspired by a noteworthy and ambitious perspective on the future of regional science, developed by Antoine S. Bailly and Lay J. Gibson on: Securing the Future of Regional Science as a Core Discipline, Studies in Regional Science, vol. 45 (2), 2015, pp. 119-125.
} 


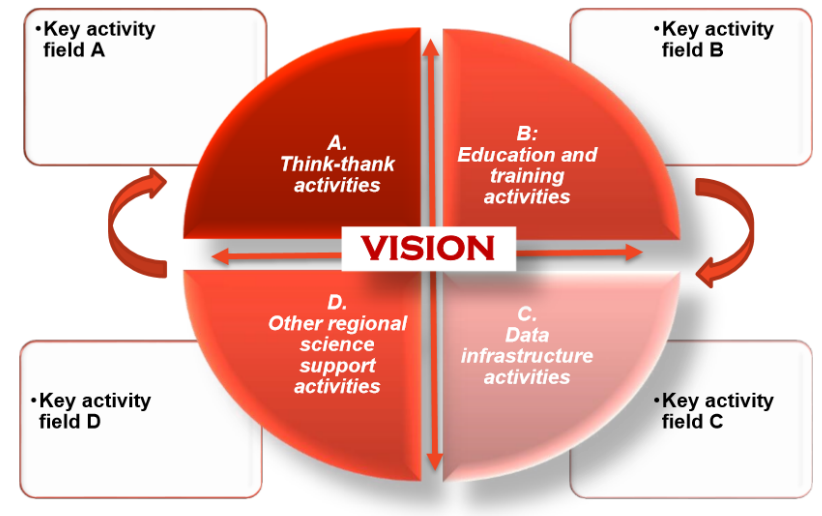

Figure 2: Regional Science Academy Action plans

\subsection{Think-tank activities}

Think-tank activities refer to forward-looking and pro-active scholarly reflections on the foundations of and future directions for regional science, be they theoretical, methodological or policy-oriented. As a first trial, various tentative ideas were already derived from a so-called 'brain-shaker' experiment ${ }^{2}$. Examples of issues to be addressed are:

- What are the prolegomena and foundations of spatial theory?

- Is the role of space in regional science a passive or an active one?

- How does space play a role (opportunity-creating or friction-creating) in a multidisciplinary orientation of regional science?

- Is there a need for designing a 'science for cities' and if so, how?

- Which megatrends in the spatial sciences can be identified that have a direct bearing on future research and policy challenges (using, for example, scenario or imagineering techniques), and how can knowledge gaps be filled from foresight experiments?

- Which are the critical grand challenges for our global space-economy which have profound urban and regional implications in the future (e,g. a post-urban society)?

- What are the long-term consequences of the continued urbanisation and the dissolution of the traditional urban-rural dichotomy? Are we moving towards a post-urban world?

- How do new findings from other disciplines (e.g., behavioural economics, experimental psychology, evolutionary sociology, network analysis, business management) impact the future of regional science?

- Has regional science a relevance for global debates on international trade, foreign migration, economic recession, emerging economies, human health, international peace, climate change policy, and the like?

A careful scoping of all such open future issues on the principles of regional science, its broader societal relevance, and its contribution to policy and smart governance would be needed. Such a systematic scoping experiment may lay the foundations for a catalytic and progressive development in auto-revitalising regional science theory, methodology and policy with a view to the future.

\footnotetext{
${ }^{2}$ This was a thought experiment among founding members to distil some first meaningful further ideas; see also K. Kourtit, T. Dentinho, P. Nijkamp and V. Royuela Mora, Envisioning Experiments on the Future of Regional Science. In: Regional Research Frontiers (R. Jackson and Schaeffer, P. eds.), Berlin: Springer-Verlag (forthcoming).
} 


\subsection{Education and training activities}

Regional science needs a solid cognitive underpinning of the human capital embodied in its scholars. In many cases, regional scientists borrow their intellectual toolboxes from other disciplines, such as economics, geography, transportation science, architecture, and political science. There is no such thing as a 'standard' regional scientist. For the sake of visibility, recognition, job profiling, and the future strength of regional science, serious attention might be given to the educational and training aspects of regional science. For example, what may we expect from a Master course on location theory or geographic information systems or, even more ambitiously, regional theory ${ }^{3}$ ? The issue of a Regional Science curriculum would certainly need a special interest group with a broad composition.

It would be highly desirable to create a portfolio of requirements or desiderata for either individual curricula (both Bachelor and post-graduate, both minor and major) which may be seen as cornerstones of a regional science education programme. Designing such a road map could be initiated with an inventory of different educational and training programmes worldwide. This might then lead to a consensual discussion on expectations regarding relevant courses, including teaching materials, textbooks, etc. This would strengthen and highlight the essence of regional science as a scientific mode.

A second strand in the category of Education and Training Activities would be the design of new themes and the organisation of intensive pedagogical Summer Institutes and the like on dedicated novel themes in regional science, where the ingredients of such an experimental course might be somewhat standardised so as to comply with international standards for scientific curricula. It may also be possible to develop digitally available curricula, e.g. as video or televideo presentations. Here, we may build on existing and new initiatives, so as to avoid overlap.

Another issue which deserves profound attention is the issue of the recognition and certification of Master's Degrees based on the content analysis of their courses (interdisciplinary regional diagnosis, regional and urban economics, spatial econometrics, regional and urban modelling, geo-science information, and policy design and evaluation). This may be related to a discussion and appraisal of papers presented by Master's students in regional science sections or supranational and world meetings.

One might also envisage the publication of free online textbooks, with the support of the various RSAI sections, translated into the main languages (English, French, Chinese, Japanese, Russian, Spanish, Portuguese, Arabic, ...), on interdisciplinary regional diagnosis, regional and urban economics, spatial econometrics, regional and urban modelling, or policy design and evaluation, and the like.

\section{'There's a way to do it better, find it' Thomas Edison}

Another related idea is to offer students the opportunity to receive a Certificate in Regional Science, whose requirements would be approved by the Regional Science Academy. To attain the certificate, the students concerned would have to complete a prescribed number of courses - perhaps 5 or 6 (including e-courses). These courses would cover the foundations of regional science in the areas of theory, methods, and practice/application. Each of these could be a track within a given curriculum. There is a number of ways in which the curriculum could be structured, e.g. with one option requiring students to take two courses in each of the aforementioned tracks. These courses would be chosen from a catalogue of approved courses. The courses in the catalogue would originate from universities across the world. This would provide students with the opportunity to take courses from prominent regional scientists from various universities around the world. Or they could take all courses from one university if enough were offered. The option to take courses from multiple institutions would allow students where regional science is less prominent to complete the certificate. For example, at the University of Toledo one might only have one or two courses that would qualify as certified courses in

\footnotetext{
${ }^{3}$ For an example the description of a Graduate Programme in Regional Science at Cornell University, see http://www.aap.cornell.edu/crp/programs/regsci/index.cfm.
} 
the catalogue. Thus, a student there could take these one or two courses and then enrol in courses at another institution (on site and/or on line) to complete the Certificate.

Clearly, to achieve these goals it will be necessary to establish a set of nodes in a worldwide educational network that can offer hosting, training, and research opportunities. This also calls for prominent committed teachers who would help establish the Academy, nurture its future development and champion new initiatives worldwide.

'Without the playing with fantasy no creative work has ever yet come to birth. The debt we owe to the play of imagination is incalculable' Carl Jung

There are of course logistical barriers to this idea - e.g. students paying for travel, housing, and tuition costs at other institutions, etc. There would need to be a Curriculum Committee of sorts to oversee the Certificate - both to approve new courses that want to be added to the catalogue, and to certify that a student has completed the requirements for the Certificate. Perhaps, a graduation ceremony could be organised at the ERSA and NARSC, AMERICAS or PRSCO meetings where students are presented with certificates. In this line of thinking, there is already a tentative list of Regional Science Schools ${ }^{4}$ where the education of regional science is taking place.

Training younger researchers with an international accredited programme will improve the social value added and the academic recognition of the field, while in the long term it may lead to an increase of resources for education and research; this should improve the amount of resources to fund the education of people from/in developing countries.

Clearly, there are many opportunities for educational cooperation among different institutions, through training programmes, sandwich programmes, and the like. Thus there is much scope for organised educational regional science initiatives, based on a distributed network structure.

'To raise new questions, new possibilities, to regard old problems from a new angle, requires creative imagination and marks real advance in science'

Albert Einstein

\subsection{Data infrastructure activities}

The development of many sciences today is centred on large information systems and data warehousing platforms (e.g. in physics, biology, climatology, bio-medical sciences, etc.). It seems promising for the future of regional science to shift from the analysis of ad hoc databases to more structured and coherent databases, to be shared with many spatial scientists world-wide. Both open-access standardised data collection and sharing are critical for collective progress in a given field of scientific research. This would enhance international cooperation and joint agenda setting. Such a plan would call for an ambitious initiative. The Regional Science Academy might act as a catalyst to design the principles of such an international cooperation initiative, to define standards, and to specify the organisational modalities. In many sciences nowadays, data infrastructures are nowadays the integrating and connecting mechanism for novel theory development and original research initiatives (e.g. in the area of physics, through CERN). It is foreseeable, that 'large spatial data' and 'data-driven theory' will become one of the new pathways in future regional science research. An exploration of such an untapped potential for regional science might be promising and might also help to pave the roadway forwards to more harmonised replication studies. Later on, the actual execution and implementation of research may be handed over to other professional bodies (e.g. RSAI).

'Science knows no country, because knowledge belongs to humanity, and is the torch which illuminates the world. Science is the highest personification of the nation because that nation will remain the first which carries the furthest the works of thought and intelligence'

Louis Pasteur

\footnotetext{
${ }^{4} \mathrm{http}$ // $/$ www.regionalscience.org/index.php?option $=$ com_k2\&view $=$ itemlist\&layout $=$ category\&task $=$ category\&id $=156 \&$ Itemid $=735$
} 


\subsection{Other regional science support activities}

The regional science field is vast. The activities of the Regional Science Academy should in particular address issues that set the agenda, and less its actual execution. The implementation step can be handed over to the field of existing organisations. This also ensures harmonious cooperation based on symbiosis. The development of regional science depends on many initiatives to be taken on a voluntary basis by individual scholars. In addition to the above-mentioned action lines, one might think of other initiatives such as:

- The strategies for better knowledge dissemination (e.g. e-platforms);

- The inclusion of regional science as one of the descriptors in the OECD database ${ }^{5}$

- The development of transformative ideas (e.g. scenarios) on the new spatial structure of our planet;

- The enhancement of liaisons with international bodies (World Bank, UN, OECD, EU, NGOs, etc.);

- The formulation of a 'code of conduct' for regional science research;

- The systematic fund raising from donors;

- The marketing of regional science in a global knowledge society, etc. through externally-oriented websites.

'Nothing in life is to be feared, it is only to be understood. Now is the time to understand more, so that we may fear less'

Marie Skłodowska-Curie

Many more activities could be envisaged, but the choice and implementation of such plans depends on the efforts and creativity of the members of the Regional Science Academy. In the course of time, several new ideas may come up and be put into practice. There is clearly a need for a 'rolling agenda'! Consequently, the design of a commonly shared road map for the Regional Science Academy should have a high priority.

\section{Epilogue}

'Learn from yesterday, live for today, hope for tomorrow. The important thing is to not stop questioning'

Albert Einstein

This Manifesto is provisional in nature, and hence is being subjected to the critical remarks of the worldwide regional science community and of spatial scientists in a more general context. The Regional Science Academy is work in progress. The basic premise of the Regional Science Academy is its goal to be instrumental in designing forward-looking initiatives (the 'Prometheus model') in order to ensure a vital and sustainable regional science field. Its added value would have to be more than merely offering a supplement to the prevailing strong research tradition that is often focussed on incremental amendments of past findings (the 'Epimetheus model'). Regional science is too precious to be left exclusively in the hands of traditional academic research, despite its great merits. Strategic planning on ways forward is a sine qua non for a permanent rejuvenation. This is a joint responsibility of the community of spatial scientists. The mobilisation of 'great minds' is a basic task for any vital science. Science innovation is a task that has a great meaning for the future of regional science, and home for the future of regional and urban development.

'The best way to think about reality, I had decided, was to get as far away from it as possible'

Haruki Murakami

\footnotetext{
${ }^{5}$ See website: http://ipscience-help.thomsonreuters.com/incitesLive/globalComparisonsGroup/globalComparisons/subjAreaSchemesGroup/oecd.html
} 